\title{
Knowledge about primary open angle glaucoma among medical students
}

\section{Nível de conhecimento sobre glaucoma primário de ângulo aberto entre os estudantes de medicina}

Thiago Gonçalves dos Santos Martins ${ }^{1}$, Ana Luiza Fontes de Azevedo Costa ${ }^{2}$, Otaviano Helene ${ }^{3}$, Paulo Schor ${ }^{1}$

Dear editor,

The article reports that medical undergraduates in the college studied showed great lack of knowledge about the primary open-angle glaucoma, a disease that, if not diagnosed and treated properly, can lead to irreversible blindness. ${ }^{1}$

The time that medicine colleges have dedicated to the teaching of ophthalmology in the last century has been reduced in all countries. ${ }^{2}$ Over the years, more and more doctors are trained without the knowledge necessary to solve the most basic ophthalmologic problems. ${ }^{3}$ Studies have recently described a worrying inability of medical students on eye exams. ${ }^{4}$

We realized that the lack of knowledge of the undergraduates is worring not only on the theoretical teaching, but also on the practical teaching of ophthalmology. We conducted a research with 133 non-ophthalmologists trained between 1967 and 2013 in two university hospitals in Brazil (the Federal University of Rio de Janeiro and the Federal University of São Paulo). In this research, we evaluated the confidence that doctors have reported in the diagnosis of hypertensive retinopathy, diabetic retinopathy, suspected excavation and papilledema by direct ophthalmoscopy examination. The questions were based on the knowledge expected by the International Council of Ophthalmology and by the Association of American Colleges for general practitioners. ${ }^{5}$ We included in the research diseases of high prevalence that threaten the life and the vision of the patients. Most doctors showed little confidence in the diagnosis of said diseases by the direct ophthalmoscopy examination. However, neurologists have shown greater security in the practical diagnosis of these pathologies. Therefore, we can assume that the post graduation in medicine is taking part in this training, which should belong to the medical graduation in the case of this important examination.

The medical school is expensive by nature, and is a part of everyone involved: students, professors and society, continued revaluation of its structure and its processes, mainly considering that time management is critical in developing an efficient medical curriculum.

The high prevalence of eye diseases in all areas of medicine requires that all doctors have the proper ophthalmologic training. This will reflect in a population with better care and greater chances of early diagnosis of diseases that threaten their vision and life.

\section{RefERENCES}

1. Martins SC, Mendes MH, Guedes RA, Guedes VM, Chaoubah A. Nível de conhecimento sobre glaucoma primário de ângulo aberto entre os estudantes de Medicina. RevBrasOftaolmol. 2014; 73(5):302-7.

2. Quillen DA, Harper RA, Haik BG. Medical student education in ophthalmology crises and opportunity. Ophthalmology 2005; 112: 1867-8.

3. Lippa LM, Boker J, Duke A, Amir A. A novel 3 - year longitudinal pilot study of medical student's acquisition and retention of screening eye examination skills. Ophthalmology. 2006; 113(1): 113-9.

4. Jacobs DS. Teaching doctors about the eye: trends in the education of medical students and primary care residents. SurvOphthalmol.1998; 42(4):3839.

5. Levy A, Churchill AJ. Training and testing competence in direct ophthalmoscopy.Med Educ. 2003;37(5):483-4.

\footnotetext{
${ }^{1}$ Universidade Federal de São Paulo, São Paulo, SP, Brazil.

${ }^{2}$ Universidade de São Paulo, São Paulo, SP, Brazil.

${ }^{3}$ Instituto de Física da Universidade de São Paulo, São Paulo, SP, Brazil.
}

The authors declare no conflitcs of interest

Received for publication 13/01/2015 - Accepted for publication 28/04/2015 